\title{
Re-invigorating the Teaching of Continuous Writing in Secondary Schools
}

\author{
Ibrahim Juliet Olufunke \\ English and Literary Studies Department, Kogi State University, Anyigba, Nigeria
}

\begin{abstract}
Mastering the writing skill especially poses enormous, but surmountable challenges to learners of English language as a second language. A good grounding in writing is however a sine qua non to any academic achievement. At the centre of the performance of Nigerian students, especially in English language in SSCE, is the aspect of continuous writing which carries highest mark in the examination. This was discovered after going through some of the Chief Examiners reports on the performance of candidates in the SSCE in English language submitted to the West African Examination Council in Lagos. It has been observed that this abysmal failure is as a result of the fact that this aspect has not been given its deserved attention in the teaching of English language in secondary schools. The general fall in the standard of the education at the tertiary institutions is the general fall in the standard of the composition skills on the secondary schools. This paper intends to suggest re-energizing of the teaching of continuous writing in Nigerian secondary schools because of its utilitarian roles in educational and other life-long pursuit of the modern world. Some practical suggestions which are hoped to be of immense benefits to both the teachers and learners of composition writing, especially at the secondary school level are proffered along this line.
\end{abstract}

Index Terms - re-invigoration, continuous writing, language teaching

\section{INTRODUCTION}

Writing is one of the four skills of language. The other three are reading, speaking and listening. Writing and speaking are the productive skills, while reading and listening are the receptive skills. The writing skill is said to be the most sophisticated of skills acquired for language learning (Wiredu and Oyeleye, 1998). For communication to be effective, writing skills require the mastery of not only the grammatical and rhetorical devices but also conceptual and judgemental elements. Since writing involves not just graphic representation of speech but the development and presentation of thoughts in a structured way, it appears to be the hardest of all the skills even for native speakers.

Weigle (2002) states that it is now widely recognized that writing plays a vital role not only in conveying information, but also in transforming knowledge to create new knowledge. It is also of central importance to students in academic and second language programmes throughout the world. Again, writing, which was once considered the domain of the elite and well-educated, has become an essential tool for people of all walks of life.

This paper therefore intends to re-examine the ways in which the teaching of continuous writing could be improved for effective communication. The paper chooses SSCE as a focus of study since that is the preliminary stage for the prospective candidates into our tertiary institutions. The idea is to forestall the falling standard of education via the falling standard of teaching and learning English language at this level.

\section{A. Statement of the Problem}

In a recent study, Aduwa-Ogiegbaen and Iyamu (2006) found out that the problems of the university education actually have roots at the secondary level. They note that it is at the secondary school level that the potential undergraduate is supposed to have been given adequate foundation in the use of English, but the fact on the ground is that the teaching and learning of this language is beset by a myriad of problems at this level. Afolayan (1995) also affirms that, generally, the English language teaching and learning efforts in Nigeria have failed to yield the expected positive results. Mohammed (1995) equally reveals that there has been a general decline in the performance of students in English in Senior Secondary Certificate Examination (SSCE) since its introduction in 1998, and a correlating failure in other subjects, particularly Biology, Chemistry, Physics and Mathematics. He rightly notes the close connection between communicative competence and educational performance generally.

Muhammed (1995) further laments that the students' overall communicative competence in English is declining, instead of improving, in spite of the fact that English is a core subject and a medium of instruction in both the JSS and SSS. This, he notes, is contrary to the normal expectation that, where a language is used as a medium of instruction as well as a core subject in an educational system, its acquisition would be smoother and constantly reinforced.

To redress the ugly situation painted above, Aduwa-Ogbiegbean and Iyamu (2006) suggest that in order to study English as a second language and be successful at it, the student must be properly helped by the teacher to acquire skill in the four language skills namely: speaking, reading, listening and writing. Ayodele, Oyeleye, Yakubu and Ajayi (1990) emphasize that as important as the possession of the language basic tools of adequate vocabulary and the mastery of the basic structure may be, these alone may not be very useful after all, if they cannot be used as tools to express suitable 
ideas. Mohammed (1995) buttresses the above fact by affirming that proficiency is best determined not by how much language one knows in the head, but by how well one can use the language to communicate and express oneself freely on any subject matter.

Silva (1993, p. 669) argues that because of the problem of limited linguistic knowledge, writing in a second language tends to be "more constrained, more difficult, and less effective than writing in a first language". He further asserts that, the second language writers generally plan less, revise for content, and write less fluently and accurately than first language writers. He continues that, in addition to limited linguistic resources, second language writers may be disadvantaged by cultural factors: they may not have awareness of the social and cultural uses of writing in second language, the appropriate ways in which functions can be expressed in writing, or the expectations of readers from a different culture. These enumerated problems are valid in the case of the Nigerian secondary school students of English who have limited knowledge in the structure of English language and the cultural nuances of the English people.

It is in line with the above stated problem of the decline in the standard of continuous writing in Nigeria, especially in the tertiary institutions as well as other general inherent problems associated with the teaching of English as second language according to Afolayan, (1995); and Aduwa-Ogbiegbaen (2009), that this paper calls for pedagogical reinvigoration and additional concerned efforts in the teaching and learning of English language at the secondary school level. This is because this is the level at which the foundation of the university education could be solidly laid. The focus of this paper is the teaching of the writing skills which have been acknowledged as arguably the most important in educational setting in terms of the utility; and at the same time, the most sophisticated and most difficult to accomplish of all the language learning skills (Oluikpe, 1979; Malinowski, 1991; Wiredu and Oyeleye, 1998).

Experience of this writer, over the years, has shown that majority of the students in our tertiary institutions lack the wherewithal to write coherent and sustained composition to explain their thoughts and ideas in assignments and examination questions; preferring, at the best, to give barren enumeration of their points, or write malnourished and undeveloped paragraphs. Students fail or score low marks in a situation like this, not because they do not have ideas of the subject-matter, but they do so because their work is haphazard, ill-planned, incoherent and shabbily executed. This unhealthy scenario probably happens because the writing skills of the concerned students were not sharpened enough at the foundational level in the secondary school.

\section{B. Objective of the Study}

The objective of the study is to explore the importance of a good grounding in writing skills to any academic achievement. Also, to forestall the foreign standard of education and to proffer ways in which writing composition can be improve for effective communication.

\section{MEthodology}

Using an eclectic approach, data came from different sources relating to the importance of writing skills to academic achievement. Information came from examination of some of the Chief examiners' report on the performance of candidates in English language examinations submitted to the West African Examinations Council, Lagos. Personal experience as a long time English language examiner (Team Leader) for both West Africa Examinations Council (WAEC) and National Examinations Council (NECO) for several years was also put into use. Some classroom teachers of English language also volunteered information concerning the negligence of some of their colleagues in the teaching of composition writing. For further verification, structured questionnaire was equally used to source information on the perceived problems of writing composition in secondary schools and way out of the problems.

\section{The Art of Continuous Writing}

In language art, the art of continuous writing is also referred to as essay writing or composition writing. Generally, writing involves putting down impressions or statements or declarations. And when the writing is done in a sustained form or manner, it grows into a composition. Depending on the situation, purpose and target audience, composition may take any of these forms: letter, essays, reports, minutes, memoranda, etc. Composition demands deep thinking and the ability to present points in an orderly manner. In presenting points in composition writing, one is expected to select relevant ones from an array of experiences which one has acquired from wide reading and one's daily interaction with friends, acquaintances, and so on. The skills necessary for writing good composition can be grouped into about five general components as follows (Wiredu and Oyeleye, 1998);

* Language use: the ability to use correct and appropriate sentences

* Mechanical skill: The ability to use correctly those conventions peculiar to the written language, such as punctuation $\mathrm{m}$ arks, spelling, etc

* Treatment of content: Ability to think creatively and develop thoughts, excluding all irrelevant information.

* Stylistic Skills: The ability to manipulate sentences and paragraphs, and use of language effectively.

* Judgement Skills: The ability to write in an appropriate manner for a particular audience in mind, together with an ability to select, organize and order relevant information.

It behooves on the teacher of composition writing to have as their objectives the inculcation of the above sub-skills in their students as they teach along. 
Suggestions for language teachers of continuous writing teachers of composition in the secondary school, as in other levels, should carefully and realistically plan the lesson for the composition class to serve two purposes: communicative and linguistic competence. For example, students in the composition class must be given motivation for the writing they are required to do. There must be an identified problem, a suitable stimulus and a clearly stated purpose for writing. This purpose must be explicitly embedded in questions, because students should not be expected to communicate in vacuum. That means there should be a clear statement of what is to be taught in the lesson and how it should be taught. The teacher could even go as far as explaining the type of writing skill intended to be taught and illustrate with interesting topics that are relevant to the students' experience. The problem to be tackled in the teaching should be identified. For instance, the problem may be how to develop paragraph or the required tense for narrative essays. This revelation can help prepare the students ahead of the real lesson.

Again, composition topics should be relevant to the background, interests and experiences of the students. For instance, current and rampant problems in the society such as students' unrest, HIV and political crises all that can easily sensitize the thinking and interest of students should be given to write on. They must be presented with the widest range of topics to write on, and their writing must be rationally directed, as in real life, to the persons expected. To realize the objective of linguistic competence, composition writing should be directed by the teacher to keep in step with the grammar and vocabulary being taught. Items of lexis and structure required for a particular topic should already have been taught. For instance, informal writings require informal style that is, familiar, natural and conversational language such as the use of Idioms, proverbs and abbreviations. In writing articles for publication, a mixture of long and short sentences with the former dominating will give a good presentation. Whereas in argumentative students should be taught how to employ contrary points to buttress their arguments and finally take a stand.

It is also expected that the teacher will stress the difference between the narrative essays and the argumentative essays that start with the vocative, Good Morning Sir/Ma, the Panel of Judges, the Time Keeper, the Co-debaters. It is equally advisable that the teacher teaches students how to use language to demonstrate their awareness of the presence of an immediate audience. Though the writing is formal, informal use of language such as 'can't', 'won't' is allowed. This will make the writing look more natural. These particular features distinguish argumentative writings from other writings and this fact should be stressed for students to take adequate precaution.

By and large, it is when the student of language is faced with the situation of putting his ideas or thoughts in writing that he realizes that the task looks simple on the surface only. As soon as the subject matter is identified, the enormity of exercise becomes clear. The teacher should inculcate the correct disposition in his students about composition writing. The students should be encouraged to see writing as a process. They must not be overtly conscious about the product. Rather, they should concentrate on the distinct but interrelated steps that must be taken during the writing process.

For a successful continuous writing, there is need for planning. Under this, the title of the essay should be the first thing to write down. Following this, the student will have to think about or mediate on the topic and then jot down points as they occur to the student. At this level, points can be jotted down in any order. An example is 'how to prepare pounded yam'. (a) cook the yam (b) pound the yam (c) peel the yam (d) wash the yam.

It is clear that to prepare pounded-yam does not come in the order given above. The next step therefore will be for the student to re-arrange these points the way they will appear in the essay. This leads the students to 'outlining' where the above steps are orderly arranged to give: (a) peel the yam (b) wash the yam (c) cook the yam (d) pound the yam. This orderliness provides continuity to the writing and as well prevents the writer from deviating from the layout of the essay.

Students in the composition class at the secondary school level should be made acquainted with the fact that writing outlines is a very important activity of the pre-writing stage of the essay. Writing outlines helps the students to plan his thought or ideas, and indeed the entire essay in an orderly manner. The student should know that any writing that does not have a well-laid outline is not likely to be a very good essay. It is in an outline that we show at a glance both the ideas contained in an essay and the way in which these ideas relate to one another.

Paragraphing: The teacher should reiterate to the students the importance of organization in composition writing. The student is expected to realize the importance attached to organization by examiners as well as the great help it can be to him. A student may fail in essay writing not because he does not have enough vocabulary, or that he does not have enough ideas to put across. He may fail because of the singular problem of ill-planning and shabby execution of the essay work. The student should therefore be instructed to be able to use the basic skills of language to build up the sentences into good paragraphs. They are expected to know how to formulate or generate ideas for the essay, how to break the ideas into manageable units, and finally how to develop the ideas into paragraphs each of which centers on one idea.

The teacher of continuous writing should endeavour to let the students know that a paragraph should contain only one point. Introducing two or more distinct points into one paragraph will make the paragraph lack unity. And if unity is to be preserved, every sentence must bear upon the new theme which the first sentence of a paragraph is expected to have expressed. This first sentence is called the topic sentence. If there are four points to be developed on a topic for instance, it means there shall be six paragraphs in all. One for introduction, four for points, and one for conclusion as illustrated below:

Topic: The issue of ' 419 ' in Nigeria. 
(1) Introduction (2) The History of '419' in Nigeria (3) How '419' operates (4) Effects on social life and economic development (5) Efforts of the Government on the problems of ' 419 '

(6) Conclusion

It must be stressed by the teacher that all forms of continuous prose are written in paragraphs. A paragraph happens to be a convenient unit of thought, discourse or composition. It is usually longer than a word, phrase or sentence, and it enables the writer to develop a unit of thought or central idea at a time. It usually has brief introduction, development and conclusion. In a sense, a paragraph can be described as a miniature essay.

Inherent in the concept of paragraphing is the idea of paragraph unity. Each paragraph revolves around one main point or a single central idea. Paragraph unity derives from the fact that there is a central idea to which all the sentences in the paragraph relate. To achieve this, there must be a key or topic sentence for every paragraph. Such a sentence encapsulates the central idea of the paragraph. It is usually located at the beginning of the paragraph by which other sentence in the paragraph will be seen to derive directly from. As a matter of fact, there should be no single unrelated sentence in the paragraph - one that does not contribute to the central idea of the paragraph.

This writer is positively disposed to the suggestion that in teaching composition writing to second language students, especially in the secondary schools, the teacher should not make too many assumptions about the ability of the students to handle structures, vocabulary and the mechanics of written expression. It has been suggested (William, 1990) that attention to details is essential in dealing with the writing problems of second language students; and the single most important recipe for the composition lesson is for the teacher to focus on one teaching point at a time. A teaching point is focused on a set of interrelated features, which make up a functioning whole. For example, in focusing on a point of tense, the writing needs to be restricted to the simple present, or the simple past tense only. Both tenses can constitute the focal point, the use of one tense being illuminated by contrast with the other.

A strong case has also been made for a judicious use of guided and controlled method of composition teaching, especially at the junior secondary school level (Oluikpe, 1979; William, 1999). This will be of immense benefits to the students at this level because the goal of controlled expression is to instill in the learners the facilities needed to produce clear piece of competition, free from all grammatical errors.

Literature plays an important role in teaching and learning to write composition. Literary works, especially the novels are exemplification of language system: the everyday language used for human communication. English and African novels with English as the language of expression contain features of the English Language used in England and Africa respectively. Features such as words and meaning, types of sentences, paragraphing, narrative, expository and descriptive passages; register and punctuation marks that abound in the novel are useful resources for teaching composition. Little wonder then when people who aspire to speak and write well are always advised to read novels.

Extracts from these novels can be made available in language classroom for practice. Students can be asked to read and summarize what each extract contains. This can help improve students' performance in essay writing, paragraph development and punctuation marks. Students can also be provided with points on particular topics and be asked to develop these points into composition. This can stimulate the students in the act of paragraph development and also enable them to use on their own, the features of English in the novel that have been acquired. This eventually can lead to effective communication in the English language. This is based on the premise that the use of language is the manipulation of fixed patterns, which are learnt by imitation; and not until these have been learnt that originality occurs in their writing endeavours.

It is also important that the teachers of composition writing impress it on their students that all the language skills are interrelated. For example, in an obvious way, writing and reading abilities are interrelated. Wide reasoning has a more profound, if subtle, effect on writing ability. As a matter of fact, the only way to write effectively is by being familiar with effective writing and learning from it in a subconscious kind of way. The learners of writing in the secondary school should not be unaware of this glaring fact.

Finally, students should be made to cultivate the habit of proper revision of their written composition and possibly give their composition to friends for further proof reading. They should be told not to allow their hand written composition or typed written compositions to get to the audience without proper revision. A research carried out by Hayes and Flower (1980) indicates that good writers spend more time planning and revising their work than novice and they tend to edit their writing for content and organization rather than simply making surface changes to the text. Expert writers also take into consideration their audience, by considering among other things what a potential reader is likely to know about the subject, how much needs to be explained and what can be left implicit, and what sort of evidence the reader will likely find impressive. It should be noted, as a matter of utmost importance, that composition teaching, like other areas in the language syllabus, should be activity-oriented. Expertise in writing comes gradually but surely when students learn to write by writing, and not by being told how to do it without practice.

Given the importance of writing skills to any academic achievement, it is surprising that, this aspect of language teaching is not given its deserved attention in secondary school, therefore the abysmal failure of students in English language yearly. The lacuna (existing gaps) that have generated this paper include the following observations.

* That inadequate attention is given to the teaching of the aspect of composition writing in English language.

* That over population is responsible for the neglect of the teaching of composition writing in English language. 
* That the general fall in the composition writing in secondary schools is responsible for the general fall in the standard of education at tertiary institutions.

* That the unqualified teachers employed to handle English language in secondary schools is responsible for the poor performance in English language in external examinations.

The inadequate responses to the above observations provide the main justification for this paper that seeks to extrapolate the merit of a good grounding in writing skills to any academic achievement.

\section{DATA/ DATA ANALYSIS}

To further prove the observed lapses in the teaching of the aspect of composition writing in English language in secondary schools and those areas that need to be focused when teaching English language in secondary schools, a structured questionnaire (50 copies) were administered to some randomly selected secondary schools English language teachers who are West African examination council examiners (markers). Only 43 copies of the 50 distributed were retrieved in May, 2021. The questionnaire touched on a number of issues surrounding the importance of writing skills to academic achievement and those factors militating against archiving this A simple percentage analysis of the 10 items produced the details below:

\begin{tabular}{|c|c|c|c|c|}
\hline & Ye & $\%$ & No & $\%$ \\
\hline 1. Do you support the use of just any graduate to teach English language. & 1 & 2.32 & 42 & 97.7 \\
\hline $\begin{array}{l}\text { 2. It is the inadequate attention given to the teaching of writing skills that is responsible for the writing skills } \\
\text { that is responsible for the mass failure in English language. }\end{array}$ & 38 & 88.4 & 5 & 11.6 \\
\hline 3. Over population affects teachers' performance in teaching English language. & 43 & 100 & & \\
\hline $\begin{array}{l}\text { 4. The general fall in the standard of education in secondary schools is responsible for the fall in the } \\
\text { standard of education in tertiary institutions. }\end{array}$ & 38 & 88.4 & 5 & 11.6 \\
\hline $\begin{array}{l}\text { 5. Parents' failure to provide reading materials in English and Literature is affecting the teaching and } \\
\text { learning of writing composition. }\end{array}$ & 30 & 69.7 & 13 & 30.2 \\
\hline 6. Failure in English language means failure in other subjects. & 30 & 69.7 & 13 & 30.2 \\
\hline 7. Giving more writing exercises to students will help improve their performance in writing composition. & 40 & 93.02 & 3 & 6.97 \\
\hline $\begin{array}{l}\text { 8. Improvement on the teaching of writing skills will improve the level of academic performance of } \\
\text { students. }\end{array}$ & 43 & 100 & & \\
\hline & \multicolumn{2}{|c|}{ Response } & Figures & $\%$ \\
\hline \multirow[t]{4}{*}{ 9. Rate the present level of performance in English language external examinations. } & \multicolumn{2}{|c|}{ Poor } & 24 & 55.8 \\
\hline & \multicolumn{2}{|c|}{ Average } & 11 & 25.65 \\
\hline & \multicolumn{2}{|c|}{ Encourage } & 6 & 13.9 \\
\hline & \multicolumn{2}{|c|}{ Significant } & 2 & 4.6 \\
\hline \multirow[t]{4}{*}{ 10. What in your opinion should be done to prevent further decline in the standard of education in schools? } & \multicolumn{2}{|c|}{ Reduces class population } & 25 & 60.46 \\
\hline & \multicolumn{2}{|c|}{ Reduce school fees } & 1 & 2.32 \\
\hline & \multicolumn{2}{|c|}{ Provide incentive to teachers } & 13 & 30.23 \\
\hline & \multicolumn{2}{|c|}{$\begin{array}{l}\text { Establish monitoring agents to } \\
\text { monitor schools }\end{array}$} & 4 & 9.30 \\
\hline
\end{tabular}

\section{Discussion}

Question One: Nearly all our respondents, 42 (97.7) to question one do not support the use of just any graduate to teach the English Language in secondary schools. This shows a significant level of awareness of the havoc such a practice had caused learners.

Question Two: Majority of our respondents to question two 38 (88.4) confessed to the negative impact the inadequate attention given to the teaching of writing skills has caused academic performance- a view that is in tandem with the position of this paper.

Question Three: All our respondents 43 (100) agreed that over population is affecting the efficiency of English Language teachers in the teaching and learning of the writing skills in English language classrooms.

Question Four: 38 of our respondents (84.4) believed that the general fall in education in secondary schools can be linked to the general fall in education in tertiary institutions. This is because the skills potential undergraduates are supposed to have possessed, in the use of English is from secondary school level.

Question Five: most of our respondents 30 (69.7) agreed that parents' failure to provide working tools-reading materials in English and Literature for students is affecting good performance in writing skills, a view shared by this paper.

Question Six: majority of our respondents $30(69.76 \%)$ believed that failure in English language means failure in other subjects. This claim is not unconnected with the fact that a failure in English language renders passes in other subjects useless as no admission can be secured into any tertiary institution without a credit pass in English language.

Question Seven: Nearly all our respondents 40 (93.03) shared the opinion that giving more writing exercises to students will help improve their writing skills. This is because teaching will be more practical as students' performance can be assessed and graded. 
Question Eight: All our respondents $43(100 \%)$ shared the opinion that improvement on the teaching of writing skills in English language will improve the level of performance in academic performance. This is supported by the fact claimed in this paper that, a good grounding in writing is since qua non to any academic achievement.

Question Nine: 30 (9.7) out of the 43 respondents rated the performance in English language as 'poor'8 (9.8) as 'encouraging; 3 (6.97) as 'average' while 2 (4.6) as 'significant'. From these responses, it is clear that the general performance of students in English language is acknowledged to be generally 'poor' i.e.69.7\%.

Question Ten: 25 of our respondents (60.46) believed that if the classroom population is drastically reduced, the class will become effectively managed. 13 (30.23) want the English language teachers remunerated for effective performance. $4(9.30)$ is of the opinion that if the government sets up an inspectorate division to monitor teachers, performance will be enhanced. 1 (2.32) believed school fees need to be reduced for teaching and learning of writing skills to be meaningful.

What one can deduce from this analysis above is that, over population in classrooms appears to be working seriously against the effective performance of teachers and learners in classrooms.

\section{CONCLUSION}

It is the contention of this writer that if the teaching of composition writing is re-vitalized and radically improved in the secondary schools along the lines suggested above, the positive band-wagon effects would be reaped in their tertiary institution where the use of English of the undergraduates and their approach to answering essay questions in their different fields of study would be enhanced. This re-invigoration is also expected to particularly stem the tide of mass failure in SSCE, and failure in other subjects as well. It is expected that the more power of expression and organization the students have in arranging thoughts and ideas logically and coherently in English language, the more they will be able to surmount all their academic hurdles, and the trend of the much talked about falling academic standard would be arrested. Outside academics, the students would be able to harness the immense potentials of the English language in Nigeria. The English Language in Nigeria today, as in the world over, is a veritable tool for the acquisition of modern knowledge and self-development of its speakers. Ultimately, the growth and development of the nation as a whole would be further enhanced.

\section{Recommendation}

As failure in the English language means failure in other subjects (failure in English hinders admission to any higher institution) and composition carries the highest mark in SSCE English paper, special attention should be given to the writing of composition by making it more practical-giving more writing exercises to students. The government also has its role to play in the area of over population in classes. If the population in each class is reduced to manageable level (45 students per class) as the practice was in the past, teachers will be able to give essay topics out to students, mark and return to students for them to know their areas of deficiency.

Parents should also endeavour to provide reading materials for their children especially English and Literature text books to enhance the teaching and learning in secondary schools.

The teaching of English Language should not be given to just any graduate but trained graduates of English that can properly handle the writing of composition.

Over population has so much discouraged teachers from given composition topics for students to write and return for grading. In the alternative many teachers have concentrated more on grammar works that have worked examples that can direct students on what to do. After the exercise, students in most cases are asked to exchange their notes to be graded by themselves. This practice has also indirectly affected writing composition as the needed grammar or appropriate lexical items for writing specific composition topics are not acquired in order to communicate effectively.

It is the belief of this writer that if all these areas mentioned above are adequately addressed by the government and the teachers of composition, both the teachers and the students will receive enough motivation to teach and write good composition.

\section{REFERENCES}

[1] Aduwa-Ogiegbaen, S.E \& Iyamu, E.O.S. (2009). 'Factors affecting quality of Language Teaching in Secondary Schools in Nigeria'. Retrieved June 17, 2009, from http://www.worldlanguage.com/Articles/52htm.

[2] Afolayan, A. (1995). 'Ineffectiveness in the Presentation of English in Nigeria: Sources and Remedies'. In A. Bamgbose; A. Banjo and A. Thomas (eds.), New Englishes: A West African Perspective (Pp. 133-129). Ibadan: Mosuro.

[3] Ayodele, S.O; Oyeleye, A.L., Yakubu, S.Y. \& Ajayi, D.A. (1990). General English: A Course for the Tertiary Levels. Ibadan: Bounty Press Ltd.

[4] Hayes, J.R, and Flower, L.S. (1980). 'Identifying the Organization Writing Process'. In L.W. Greg \& E,R, Steignberg (eds.). Cognitive Process in Writing (Pp. 31-50). Hillside, N.J: Lawrence Erilbanm Associates.

[5] Malinowski, P.A. (1991). A Writing course Designed for Development of College Students. New York: Community College of the Finger Lakers.

[6] Oluikpe, B.O. (1979). 'Teaching the Art of Continuous Writing in Tertiary Education'. In E. Ubahakwe (ed.) The Teaching of English Studies (Pp. 137-150). Ibadan: Ibadan University Press. 
[7] Mohammed, A. (1995) 'Communicative Competence Acquisition in Infelicitous Learning Environments: the problem with SSS English in Nigeria'. In A. Bamgbose; A, Banjo \& A. Thomas (eds.), New Englishes in West African Perspective (Pp. 130-152). Ibadan: Mosuro.

[8] Silva, T. (1993). 'Towards an understanding of the distinct nature of second language writing: The ESL research and its implications'. TESOL Quarterly 27, 657-779.

[9] Weigle, S.C (2002). Assessing Writing. Cambridge University Press.

[10] William, D. (1990). English Language Teaching: An Integrated Approach. Ibadan: Spectrum Books Limited.

[11] Wiredu, J.F. \& Oyeleye, A.L. (1998). Aspects of Functional English. Ibadan: Hope Publications.

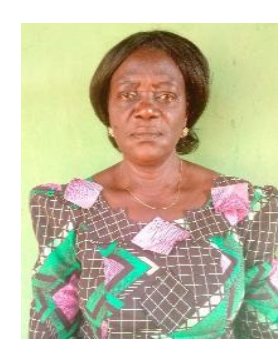

Juliet Olufunke Ibrahim born on the $21^{\text {st }}$ Oct, 1962. She has Awards in BA ENGLISH LANGUAGE in University of Ilorin, Ilorin, Nigeria (1981), MA ENGLISH LANGUAGE in University of Ilorin, Ilorin Nigeria (1990), PHD ENGLISH LANGUAGE at Ahmadu Bello University Zaria (2012). The Author's specialized on socio-linguistics.

She has a working experience at Kogi state University Anyigba, Kogi State, Nigeria where she LECTURED as a senior Lecturer.

Dr. Ibrahim has memberships with ANA - Association of Nigeria Author and LAN- Linguistics Association of Nigeria. 